\title{
Mehr Leistung beim Schleifen
}

\author{
Eine neue Generation Steuergeräte für Handstücke und Mikromotoren arbeitet \\ geräuschmindernd und bietet eine höhere Drehleistung.
}

Eine neue Generation Steuergeräte (EneskaMicro), die systemübergreifend und abwärtskompatibel ist, stellt joke Technology vor. So lassen sich die meisten Handstücke und Mikromotoren verschiedenster Hersteller mit den neuen Geräten steuern. Außerdem wurden die gesamten technischen Parameter, wie zum Beispiel die Drehzahlleistung, deutlich erhöht. Besonders die speziell entwickelten Handstücke und deren Spannkraft machen die neuen Geräte für Anwendungen mit extrem harten Materialien sehr interessant - beispielsweise bei Arbeiten im Aerospace-Bereich.

\section{Eigenentwicklung bei Motoren und Handstücken}

Die neue Generation hat eine um 20 Prozent höhere Enddrehzahl und 30 Prozent mehr Leistung. Die um 50 Prozent höhere Spannkraft bei den neu entwickelten Handstücken, überzeugt vor allem bei Fräsarbeiten. Denn die Kombination von Feder- und Hebelkraft bewirkt, dass der Fräser auch bei hoher Belastung seine Position hält. Dies kann bei neuen Anwendungsbereichen von Vorteil sein, beispielsweise bei der Bearbeitung von hochchromigen Stählen, Inconel oder Titan wie bei der Implantatfertigung. Alle Achsen sind hochpräzise geschliffen und mit Lagern der neuesten Generation verbaut. So wird eine hohe Rundlaufgenauigkeit erzielt, die kleiner als 0,01 Millimeter ist und neben der präzisen auch ein noch vibrationsärmeres Arbeiten möglich macht.

\section{Kein Staub, kein Krach}

Das Steuergerät kommt ohne Lüfter aus, was weniger Geräusche und somit weni-

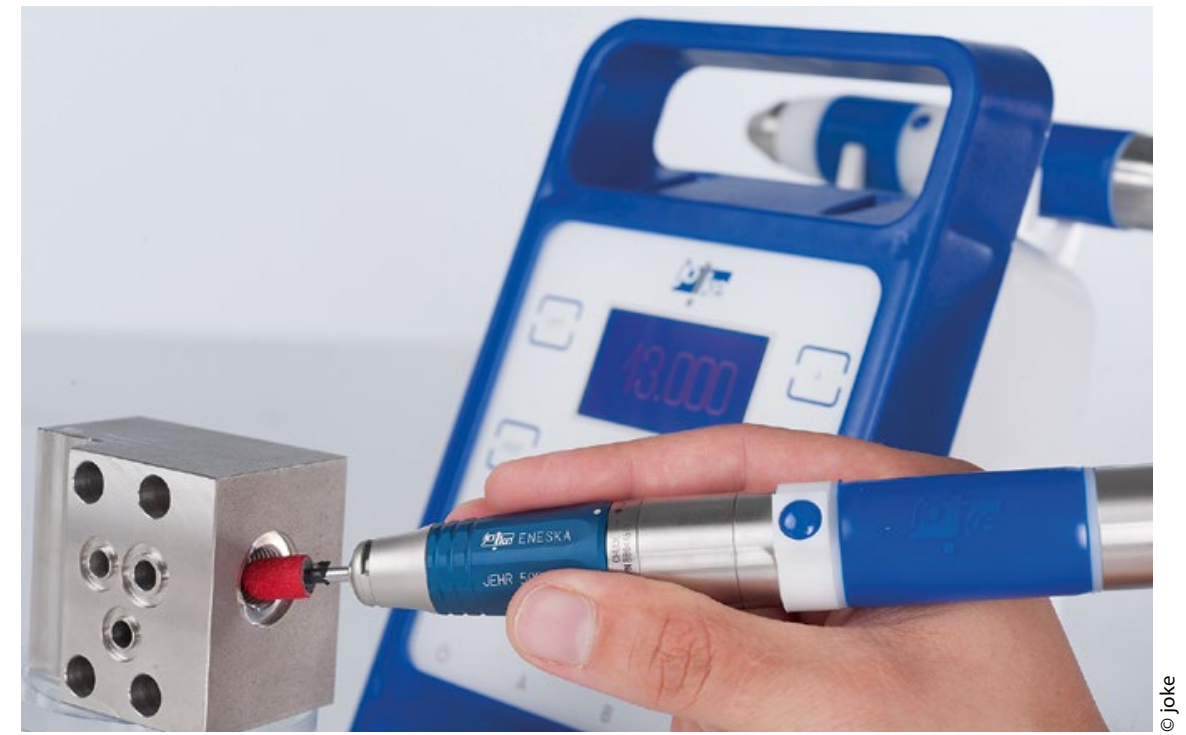

Anwendung des neuen Steuergeräts an einem Hydraulik-Block.

ger Belästigung für den Anwender bedeutet. Da keine Schlitze im Gehäuse existieren, ist das Steuergerät auch staubgeschützt. Für den Werkzeugwechsel ist nun kein Werkzeug mehr nötig. Außerdem ist das Gerät sehr leicht zu warten, verfügt über einen tiefen Schwerpunkt und ist deshalb sehr standfest. Die neu entwickelten Handstücke sind etwas größer und mit einer gummierten Oberfläche versehen. Sie liegen angenehm in der Hand und ermöglichen auch längeres Arbeiten ohne Ermüdung. Für schwer zugängliche Bereiche gibt es ein neues Handstück mit längerer Achse.

\section{Steuerung mit Touchdisplay}

Auf dem Touchdisplay des Steuergeräts lassen sich mit Stationstasten die indivi- duellen Einstellungen speichern. Für die Drehzahl wurde ein Drehgeber mit einer sehr feinen Rasterung verwendet. Die Regulierung der Drehzahl kann auch optional über einen Fußschalter erfolgen. Ein entsprechender Anschluss befindet sich auf der Rückseite des Gehäuses. Das System verfügt über einen Überlastungsschutz und einen Selbstanlauf. //

\section{Kontakt}

joke Technology GmbH

Bergisch Gladbach,

Tel. 02204839547

b.lucke@joke.de,www.joke.de 